Conclusion This study informs a deeper understanding of how epistemic trust may be built in therapeutic work with adopted children and identifies possible clinical approaches that may be used by clinicians working with this client group.

\section{LINKED LIVES AND EVOLVING RELATIONSHIPS OF TRUST IN GENOMIC MEDICINE}

S Weller*, K Lyle, L Ballard, A Lucassen. University of Southampton, UK

10.1136/bmjopen-2021-QHRN.43

Background In areas of medicine such as genomics, understanding the experiences of an individual patient is insufficient because they are likely to have family members who may be directly affected by the outcome of a genomic test. Work in this field often focuses on the perspectives of health professionals, for example, in relation to how sharing 'results' might damage familial trust.

Aim To provide new knowledge about the ways in which existing relationships of (mis)trust within families shapes patient's willingness to discuss and share information with others.

Methods Taking a qualitative longitudinal approach, we documented the journeys of patients and their families as they experienced genomic testing to understand how, over time, the process impacts on their lives and relationships. The project forms part of a Wellcome Trust collaborative award focusing on the ethical and social challenges that arise for health professionals, patients and families, working and living with genomic results. Repeat in-depth interviews with patients and their families were conducted. The purposive sample was stratified by those affected by a rare disease or cancer. Situational and diachronic/longitudinal analysis were employed.

Results Drawing on the notion of linked lives from lifecourse research, we argue that patients' views on the sharing of genetic information needs to be explored in relation to the matrix of familial relationships of trust in which they are located (or detached). This enables a greater appreciation of how trust shapes and is shaped by the sharing/withholding of different aspects of the journey through genomic testing. Moreover, the ways in which different health professionals and their practices feature in these matrices at different points in patient's journeys is also salient.

Conclusions An understanding of the complexity of such trust relationships highlights how consent processes are often deficient in capturing the range of decisions that need to be made.

\section{Theme: Methodological innovations: exploring methods and concepts for exploring trust within research}

\section{Day 1: Thursday $18^{\text {th }}$ March $-13.35-14.55$}

\section{TRUST, LOCAL KNOWLEDGE AND LOCAL ACTION}

R Duncombe*, M Pawar. University of Queensland and Charles Sturt University, Australia
This paper discusses trust and relationship in a piece of practice research that investigated health service access for people living homeless in a rural coastal town. The research used conversations with two socially disparate groups of participants; people living homeless and people providing services.

As a long term resident, staff member of the Health Service and regular attendee of a Breakfast for people living homeless, my position as a social worker was both highly transparent, and socially located between the two groups of participants.

Both experiential and observational data was collected using an inclusive action research methodology.

Reflection on the social action and the qualitative data analysis show that working with a population living with significant vulnerability requires a researcher to be authentic and dependable to ensure their trust. Working with providers with significant time restraints requires a researcher to be organised and efficient. These characteristics are different elements of trust on which both the recruitment and conduct of this research was dependent. Trust was dependent on and arose from; trust in the Health Service, trust in the Breakfast and trust in the researcher personally.

The District Oral Health Service was subsequently able to act on the basis of this locally constructed knowledge to provide access to the public dentist using the strategy designed by the people living homeless themselves. Council also used the knowledge to contribute to a significantly reviewed policy for dealing with non-compliant campsites of those living homeless.

Based on these outcomes, the paper argues for the value of practice based, action-oriented research in small communities that draws on trust in local institutions and personnel. The process and outcome of this research has implications for inclusion in knowledge building as a powerful strategy for local action on national issues.

\section{MISTRUST IN ETHNOGRAPHY - SHOULD WE BE WORRIED ABOUT BETRAYING OUR RESEARCH SUBJECTS?}

P Pushkar. University of Manchester, UK

\subsection{6/bmjopen-2021-QHRN.45}

This article explores the analytical usefulness of mistrust in ethnographic research. I ground my argument through reference to my own fieldwork in which I did participant observation with political activists campaigning against cuts and privatisation in the NHS.

Engaging in relationships characterised by mistrust is unavoidable for most people and most ethnographers. I argue that although reflection on such engagements can be uncomfortable, they can shed light on what matters to researchers, namely, the nature of social relations.

Recent anthropological literature is increasingly rejecting previous conceptualisations of mistrust simply as the absence of trust. Mistrust is better theorised as a particular way of managing uncertainty in social relations. However, the recent literature on mistrust has not been applied to the relationship between researcher and subjects of research. 